\title{
A career in translational research: The road not taken
}

\author{
David R. Jones, MD
}

\author{
From the Department of Surgery, Memorial Sloan Kettering Cancer Center, New York, NY. \\ Disclosures: Author has nothing to disclose with regard to commercial support. \\ Received for publication April 21, 2016; accepted for publication April 26, 2016; available ahead of print May 19, \\ 2016. \\ Address for reprints: David R. Jones, MD, Thoracic Surgery Service, Department of Surgery, 1275 York Ave, \\ Box 7, Memorial Sloan Kettering Cancer Center, New York, NY 10065 (E-mail: jonesd2@mskcc.org). \\ J Thorac Cardiovasc Surg 2016;152:367-8 \\ $0022-5223 / \$ 36.00$ \\ Copyright (C) 2016 by The American Association for Thoracic Surgery \\ http://dx.doi.org/10.1016/j.jtcvs.2016.04.076
}

As suggested by Rajagopal and Whitson ${ }^{1}$ in their article in this issue of The Journal, an academic career with an emphasis on translational research is challenging and requires planning, commitment, and mentorship. Like many journeys, the path holds surprises, and the destination is not assured. Nor is the translational route appropriate for all young cardiothoracic surgeons. In choosing the road not taken, however, there are unique opportunities to make a difference and contribute to new knowledge with potential novel therapeutic or diagnostic applications.

Real and perceived barriers to a successful career in translational research include clinical pressures to generate relative value units and increase clinical volumes, poor mentorship, decreased remuneration, and, frankly, the uncertainty of success when contrasted with the rewards of clinical care. The primary reason that cardiothoracic surgeons fail to achieve success in their fledgling translational research careers, however, is the lack of a "culture of research" at their institution. This culture begins with the chair or service chief, who typically has established a robust research career in the laboratory and has recruited several like-minded faculty members through the years. Most of these individuals have achieved success, as defined by R01 or equivalent funding (eg, Department of Defense, American Heart Association, American Cancer Society), and are supported in and respected for their academic achievements. Another reason for failing to maximize one's translational research potential is a lack of appreciation of the importance of "preparation to play." Understanding what is quality research, how to do research, and what is fundable research requires more than a "don't give up" approach-it requires almost daily practice. As Malcolm Gladwell notes in his book Outliers, ${ }^{2}$ it is a rare event for a primacy of talent to result in expertise in a specific field. Expertise requires 10,000 hours of concentrated practice in an environment of protected time with adequate financial support. In essence, as all coaches say, you play the way you practice. Relevant to a career in translational research, this means that experiments will fail, grants will not be funded, money will be tight, and your work will not be accepted for publication in high-impact journals every time. With

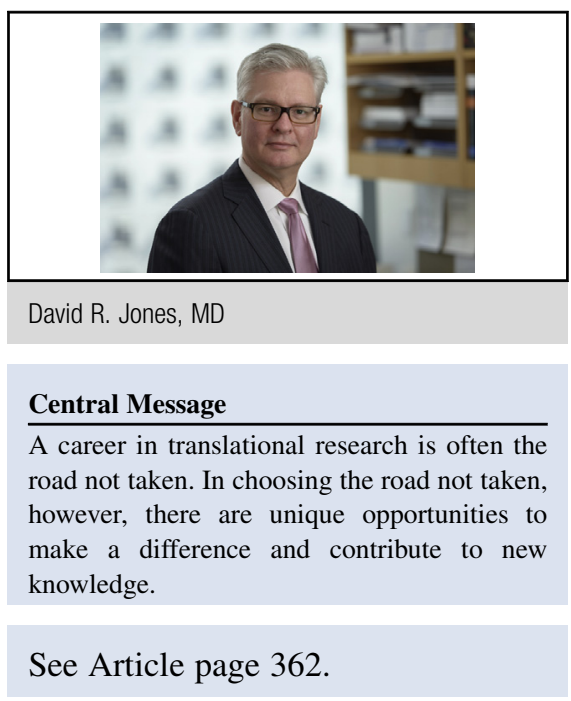

concentrated effort and hard work, however, selected critical experiments will work, grants will be funded, and you will publish high-impact articles. Success also requires a convergence of spectacular opportunities, which in my opinion is most likely to happen in a culture of research. This is why finding the right research environment, institution, surgical colleagues, mentor, and field of study for a young surgeon-scientist's first job is so critically important.

There are several misconceptions that may cloud the judgment of an otherwise discerning junior faculty member and dissuade him or her from pursuing a career in translational research. Some believe that surgeon-scientists cannot operate. This is a fallacy. Some of the most technically gifted cardiothoracic surgeons I know are superb, wellfunded researchers. Another misconception is that researchers cannot develop into leaders in our specialty. Again, many internationally recognized leaders in cardiothoracic surgery are surgeon-scientists who are leading sections, divisions, departments, centers, and health care systems. A final misconception is that surgeons cannot successfully compete with $\mathrm{PhD}$ researchers for extramural funding and produce high-impact research. Once again, many cardiothoracic surgeons have made seminal discoveries related to transplantation, thoracic oncology, myocardial protection, and structural heart disease.

Choosing to pursue a career in translational research is often the road not taken. As suggested by Robert Frost, ${ }^{3}$ however, in his oft quoted poem (excerpted here), surgeonscientists can have amazing careers, make a difference in the lives of their patients, and foster a love for discovery and innovation in the next generation of surgeon-scientists. 
I shall be telling this with a sigh

Somewhere ages and ages hence:

Two roads diverged in a wood, and I-

I took the one less traveled by,

And that has made all the difference.

\section{References}

1. Rajagopal K, Whitson BA. Basic and translational research careers as early faculty cardiothoracic surgeons-perspectives from two young investigators. J Thorac Cardiovasc Surg. 2016;152:362-6.

2. Gladwell M. Outliers: the story of success. New York: Back Bay Books; 2011.

3. Frost R. The road not taken. In: Lathem EC, ed. The poetry of Robert Frost: the collected poems, complete and unabridged. New York: Henry Holt; 1979.

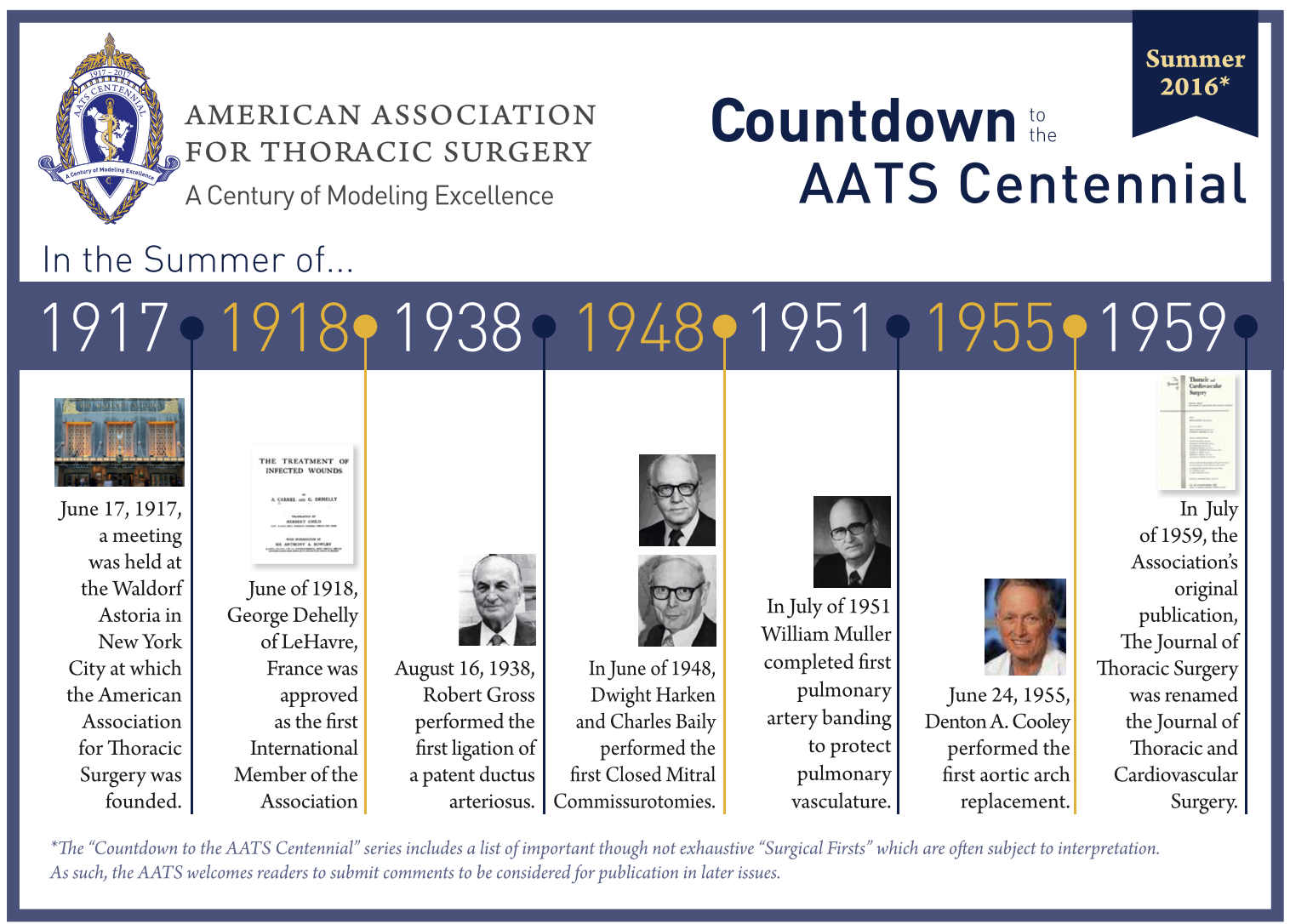

